\title{
Effectiveness of One Minute Preceptor Teaching in Improving Clinical Skills of Nursing Undergraduate Students
}

\author{
Madhuri Shambharkar ${ }^{1}$ Achita Sawarkar², Jaya Khandar ${ }^{3}$, Prerana Sakharwade ${ }^{4}$, Sonali Kolhekar ${ }^{5}$ \\ 1,2,3 Department of Community Health Nursing, Smt. Radhikabai Meghe College of Nursing, Datta Meghe \\ Institute of Medical Sciences (Deemed to Be University), Sawangi (M), Wardha, Maharashtra, India. 4,5 \\ Department of Child Health Nursing, Smt. Radhikabai Meghe College of Nursing, Datta Meghe Institute \\ of Medical Sciences (Deemed to Be University), Sawangi (M), Wardha, Maharashtra, India.
}

\section{ABSTRACT}

\section{BACKGROUND}

Nurse educator has to do clinical teaching when students are posted either in clinical or community field. Clinical teaching is a method of teaching to an individual or group of students who came in contact with patients when they are posted in clinical or in community field. Clinical education enhances appropriate link between theory and practice and at the same time provides opportunity to have a practice on how to solve complex problems of health care, provide safe care and enhance critical thinking. The objectives of the study were to inform nursing undergraduate students regarding one-minute preceptor (OMP) model, assess perception level of experimental group of students regarding OMP and evaluate the improvement in clinical skills of nursing undergraduate students through one-minute preceptor teaching.

\section{METHODS}

Experimental research design was used. Probability sampling technique was used for the selection of nursing undergraduate students and random sampling method for formation of 2 groups of the students. Total 60 students participated. Likert scale was used to assess perception level and response of students.

\section{RESULTS}

In the present study, $70 \%$ students had very good level of perception and (30\%) had excellent level of perception regarding OMP. Response regarding community posting mean score and standard deviation of both groups was $46.50 \pm 2.46$ and $35.60 \pm 3.60$ respectively. Comparison was done between the experimental and control group and $\mathrm{P}$-value was $\mathrm{P}=0.00$.

\section{CONCLUSIONS}

OMP module is effective to improve clinical skill to manage minor ailments, to make decision and critical thinking at community setting. It can be implemented to the final year undergraduate nursing students and post graduate nursing students.
Corresponding Author: Madhuri Shambharkar,

Department of Community Health Nursing, Smt. Radhikabai Meghe College of Nursing, Datta Meghe Institute of Medical Sciences (Deemed to Be University),

Sawangi (M), Wardha, Maharashtra, India. E-mail:mnnaik91@gmail.com

DOI: $10.14260 / j e m d s / 2021 / 199$

How to Cite This Article:

Shambharkar M. Sawarkar A, Khandar J. et al Effectiveness of one minute preceptor teaching in improving clinical skills of nursing undergraduate students. J Evolution Med Dent Sci 2021;10(13):920924, DOI: $10.14260 / \mathrm{jemds} / 2021 / 199$

Submission 29-10-2020,

Peer Review 30-01-2021,

Acceptance 06-02-2021,

Published 29-03-2021.

Copyright (c) 2021 Madhuri Shambharkar. et al. This is an open access article distributed under Creative Commons Attribution License [Attribution 4.0 International (CC BY 4.0)]

\section{KEY WORDS}

Effectiveness, One-Minute Preceptor, Clinical Skill 


\section{BACKGROUND}

In preparation of professional practice, the clinical setting is the place where the students come in contact with patients for the purpose of testing theories and learning skill. ${ }^{1}$ Clinical education provides the students with appropriate clinical experiences through the learning activities which are strategically planned and provided to the students. It also enhances appropriate link between theory and practice and at the same time provides opportunity to have a practice on how to solve complex problems of health care, provide safe care and enhance critical thinking. ${ }^{2}$ Critical thinking, decision making power and special psychomotor skill is important to do practice in clinical setting. Clinical teaching learning activity must focus on essential knowledge and skill. The nursing educators should have to prepare future nurses to develop critical thinking skill in them. ${ }^{3}$

Community nursing diagnosis is a report that made by a nurse through collecting subjective and objective data from the client to concentrate on patient care. This nursing diagnosis will help to plan the care. In this process nurse has to take clinical decision based on collected data from the client. A diagnosis involves a personalised approach to the situation, personal preferences and needs of the patient by directing the enduring components of the nursing process. ${ }^{4}$

It is recommended that nursing diagnosis be presented within the context of the entire nursing process and be part of the orientation program. Planning group and individual conferences in the clinical area is essential to implementation of the concept of nursing diagnosis. Home health agencies and long-term care facilities have great potential for contributing to the development of the taxonomy for nursing diagnosis. It is in these settings that the nurse functions with a great deal of independence as a primary health care provider. Therefore, nurses in community health settings should seriously consider the potential of nursing diagnosis to contribute to the development and refinement of nursing practice. ${ }^{5}$

Community health nurses have to provide care in community setting with available resources in a creative way. So, these nurses should be excellent in clinical skill, knowledge and critical thinking. Also, they should be able to apply this in practice. Self-reliance, flexibility and adaptability are essential for working independently. ${ }^{6}$ While coming to a diagnosis, the community health nurse has to address environmental and socioeconomic problems of the family. A community health nurse should assist in alteration in family health management and spread awareness about the need for infant immunizations.

The primary goal of community-based care is to improve health status of community people from a particular disease. Secondary goal is prevention and promotion of health of people and awareness of risk factors among people. Example is adults who are obese are at potential risk to develop diabetes. Another goal is to improve the health status of healthy people those are at risk to develop disease, such as teenage girls who are sexually active but not practicing safe sex.

Models of teaching gives systematic framework for theory as well as clinical teaching. Five micro skills are provided in one minute preceptor (OMP) model to improve learning experience of students in clinical setting. ${ }^{7}$ OMP model of teaching helps the nursing students to develop critical thinking through five micro skills. In this teaching model teacher can assess the knowledge of student as well as can give feedback instantly. The advantage of this OMP teaching method includes participation of patients, development of five micro skills by students and feedback by the teacher. Five micro skills are 1 . Get a commitment - motivate the students to develop clinical reasoning and to make diagnosis. 2. Probe for supporting evidence - probe the student for clinical evidence on his previous statement. 3. Reinforce what was done well - appreciate the student for his good knowledge or critical thinking. 4. Give guidance about errors - tell the student about his/her mistakes and ask him/her to do the correction or to improve. 5. Teach a general principal - guide the student in such a way so that he/she can remember these principles and apply in future. ${ }^{8}$ One-minute preceptor model can be used in advanced nursing practice for new graduate nursing students to practice in various areas such as hospital as well as in community setting. ${ }^{9}$

\section{Objectives}

The objectives of the study were to inform nursing undergraduate students regarding one-minute preceptor (OMP) model, to assess perception level of experimental group students regarding OMP and to evaluate the improvement in clinical skills of nursing undergraduate students through oneminute preceptor teaching.

\section{METHODS}

Post-test experimental design was selected for this study. The study was conducted in community field in Seloo, district Wardha. Data collection was done from September 2019 to December 2019. The population of the study was final year basic BSc. nursing students. Sample size was $N=60$. Students those who were posted in community field and were interested and gave consent to participate in the study were included in the study. Those who were not interested in participating were not included in the study. The sampling technique used for this study was simple random probability technique. Students were divided into two groups experimental and control. Experimental group was explained first about the one-minute preceptor model. Both the groups were posted in community field for two months. One-minute preceptor model was implemented for experimental group students during this one month. According to OMP 1. Get a commitment - students made provisional diagnosis after data collection and physical examination. 2. Probe for supporting evidence - asking the students about the basis on which they made the diagnosis. 3. Reinforce what was done well appreciating the students for their good knowledge and for making correct decision. 4. Give guidance about errors students were informed about the mistakes done while doing assessment of patients so that they can improve and avoid repetition of the same mistakes next time. 5. Teach a general principal - supervise the students and guide them so that they can remember these principles and apply in future. These students had selected families; they collected history from patients and family members. They made provisional diagnosis on the basis of data collection. Researcher observed these students and gave feedback to them and they accepted it 
and made improvement in them. Control group students also completed their posting in two months. They also selected families, made provisional diagnosis, provided care in the family on the traditional basis learning. At the end of posting, feedback form was given to each student and their response was collected. Two different five-point Likert scale was used for data collection. First Likert scale was used only for experimental group to assess perception of students regarding OMP. Students' perception was measured from strongly disagree to strongly agree and score ranged from 1 to 5 . Second Likert scale was used for both groups to measure response of students regarding their community posting experience. Students' response was measured on Likert scale from strongly disagree to strongly agree and score ranged from 1 to 5 . Written consent was obtained from the head of the family. Result was analysed by using Statistical Package for the Social Sciences (SPSS) version 16.0. Descriptive analysis of quantitative parameters was expressed in frequencies, percentage, means and standard deviation. The study was approved by the institutional ethical committee (IEC). Registration number ECR / 440 / Inst / MH / 2013 / RR-2016 and the study was conducted in accordance with the ethical guidelines prescribed by central ethics committee on human research.

\section{RESULTS}

\begin{tabular}{|c|c|c|c|c|}
\hline \multirow{2}{*}{$\begin{array}{l}\text { Level of } \\
\text { Perception }\end{array}$} & \multirow{2}{*}{$\begin{array}{l}\text { Score } \\
\text { Range }\end{array}$} & \multirow{2}{*}{$\begin{array}{l}\text { Percentage } \\
\text { Score }\end{array}$} & \multicolumn{2}{|c|}{ Perception Score } \\
\hline & & & Frequency & Percentage \\
\hline Poor & $1-12$ & $0-20 \%$ & 0 & \\
\hline Average & $13-24$ & $21-40 \%$ & 0 & \\
\hline Good & $25-36$ & $41-60 \%$ & 0 & \\
\hline Very good & $37-48$ & $61-80 \%$ & 21 & $70 \%$ \\
\hline Excellent & $49-60$ & $81-100 \%$ & 09 & $30 \%$ \\
\hline \multicolumn{3}{|c|}{ Minimum } & \multicolumn{2}{|c|}{37} \\
\hline \multicolumn{3}{|c|}{ Maximum } & \multicolumn{2}{|c|}{51} \\
\hline \multicolumn{3}{|c|}{ Mean \pm SD } & \multicolumn{2}{|c|}{$45.87 \pm 3.40$} \\
\hline \multicolumn{3}{|c|}{ Mean percentage score } & \multicolumn{2}{|c|}{$76.45 \%$} \\
\hline \multicolumn{5}{|c|}{$\begin{array}{c}\text { Table 1. Assessment of Perception Level of Experimental Group } \\
\text { Students Regarding One Minute Preceptor (OMP) }\end{array}$} \\
\hline $\mathrm{N}=30$ & & & & \\
\hline
\end{tabular}

\begin{tabular}{|c|c|c|c|}
\hline $\begin{array}{l}\text { Sl. } \\
\text { No }\end{array}$ & Item & $\begin{array}{c}\text { Mean } \\
\text { Perception } \\
(\mathrm{N}=\mathbf{3 0})\end{array}$ & $\begin{array}{l}\text { Standard } \\
\text { Deviation }\end{array}$ \\
\hline 1 & $\begin{array}{l}\text { Committed diagnosis and exhibited proper } \\
\text { decision making }\end{array}$ & 3.5 & 0.73 \\
\hline 2 & $\begin{array}{l}\text { Gave reasoning behind his decision expressed } \\
\text { knowledge of medical facts and analytical } \\
\text { skills. }\end{array}$ & 3.5 & 0.49 \\
\hline 3 & Received the feedback positively & 3.83 & 0.59 \\
\hline 4 & Feedback was helpful & 3.53 & 0.73 \\
\hline 5 & $\begin{array}{l}\text { Could understand why he was correct or } \\
\text { incorrect }\end{array}$ & 4.06 & 0.82 \\
\hline 6 & $\begin{array}{l}\text { Received suggestions for improvement in a } \\
\text { positive way. }\end{array}$ & 3.66 & 0.47 \\
\hline 7 & Could understand the general rule which i told & 4 & 0.64 \\
\hline 8 & Felt motivated for outside reading & 3.6 & 0.49 \\
\hline 9 & OMP helps to gain confidence & 4.03 & 0.55 \\
\hline 10 & $\begin{array}{l}\text { OMP helps to evaluate strength and weakness } \\
\text { in you }\end{array}$ & 3.9 & 0.30 \\
\hline 11 & Environment created by OMP it was good & 4.03 & 0.55 \\
\hline 12 & OMP helps to improve clinical skills. & 4.3 & 0.46 \\
\hline \multicolumn{4}{|c|}{$\begin{array}{c}\text { Table 2. Assessment of Perception of Experimental Group Students } \\
\text { Regarding OMP }\end{array}$} \\
\hline & & & \\
\hline
\end{tabular}

$(0 \%)$ had poor, average and good perception, $(70 \%)$ had very good level of perception and (30\%) had excellent level of perception level. The minimum score was 37 and the maximum score was 51 , the mean score for the perception level was $45.87 \pm 3.40$ and mean percentage was $76.45 \%$.

The perception of experimental group students regarding OMP. Findings showed that most of the students strongly agreed for why they were correct or incorrect (4.06), students understood the general rule which the researcher told them, ${ }^{4}$ OMP helps to gain confidence (4.0), they were happy with the environment created by OMP (4.03), students agreed that OMP helped to improve clinical skills (4.3).

\begin{tabular}{|c|c|c|c|c|}
\hline \multirow{2}{*}{$\begin{array}{l}\text { Level of } \\
\text { Response }\end{array}$} & \multirow{2}{*}{ Score Range } & \multirow{2}{*}{ \% Score } & \multicolumn{2}{|c|}{ Response Score } \\
\hline & & & Frequency & Percentage \\
\hline Poor & $1-12$ & $0-20 \%$ & 0 & \\
\hline Average & $13-24$ & $21-40 \%$ & 0 & \\
\hline Good & $25-36$ & $41-60 \%$ & 0 & \\
\hline Very good & $37-48$ & $61-80 \%$ & 24 & $80 \%$ \\
\hline \multirow[t]{5}{*}{ Excellent } & $49-60$ & $81-100 \%$ & 06 & $20 \%$ \\
\hline & Minimum & & & 1 \\
\hline & Maximum & & & 1 \\
\hline & Mean \pm SD & & 46. & \pm 2.46 \\
\hline & ean percentage sc & & & $5 \%$ \\
\hline \multicolumn{5}{|c|}{ Table 3. Response Assessment of Experimental Group } \\
\hline $\mathrm{N}=30$ & & & & \\
\hline
\end{tabular}

The above table shows that ( $80 \%$ ) had very good response and (20\%) of participants had excellent response and no one had poor, average or good response regarding their community posting. The minimum score was 41 and the maximum score was 51 , the mean score and standard deviations for the test was $46.50 \pm 2.46$ respectively and mean percentage of response was $77.5 \%$

\begin{tabular}{|ccccc|}
\hline $\begin{array}{c}\text { Level of } \\
\text { Response }\end{array}$ & $\begin{array}{c}\text { Score } \\
\text { Range }\end{array}$ & $\begin{array}{c}\text { Percentage } \\
\text { Score }\end{array}$ & $\begin{array}{c}\text { Response Score } \\
\text { Frequency }\end{array}$ & Percentage \\
Poor & $1-12$ & $0-20 \%$ & 0 & \\
Average & $13-24$ & $21-40 \%$ & 0 & $73.33 \%$ \\
Good & $25-36$ & $41-60 \%$ & 22 & $26.67 \%$ \\
Very good & $37-48$ & $61-80 \%$ & 08 & 31 \\
Excellent & $49-60$ & $81-100 \%$ & 0 & 45 \\
& Minimum & & $35.60 \pm 3.60$ \\
Maximum & Mean \pm SD & $59.33 \%$ \\
\hline Mean percentage score & \\
\hline Table 4. Response Assessment of Control Group \\
\hline N = $30 \quad$
\end{tabular}

The above table shows that (73.33\%) had good level of response and (26.67\%) had very good level of response and no one had average, poor or excellent level of response. The minimum score was 31 and the maximum score was 45 , the mean score and standard deviation for the test was $35.60 \pm$ 3.60 respectively and mean percentage of response was 59.33 $\%$.

\begin{tabular}{|lccccc|}
\hline \multicolumn{1}{|c}{ Overall } & Mean & SD & Mean \% & t-Value & P-Value \\
\hline Control group & 35.60 & 3.60 & $68.8 \%$ & 12.80 & 0.00 \\
Experimental group & 46.50 & 2.46 & $82.2 \%$ & & Sp $<0.05$ \\
\hline Table 5. Comparison between Experimental Group and Control Group \\
\hline N = 30
\end{tabular}

Table 5 depicts the overall mean response scores of control group and experimental group which reveals that experimental group mean score was higher 46.50 with SD of \pm 
2.46 when compared with control group mean score value which was 35.60 with SD of \pm 3.60 . T-value was 12.80 and Pvalue was 0.00 . So, it is highly significant.

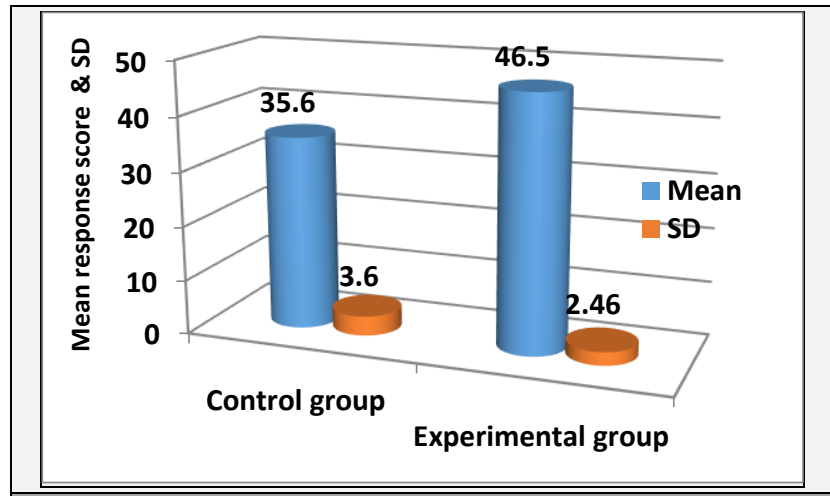

Figure 1. Comparison between Experimental Group and Control Group

\section{DISCUSSION}

After completion of graduation in nursing, students can do independent job in primary health centres or sub centres. So, they should be able to treat minor ailments, to take prompt decision, to make diagnosis and to refer the patient according to their condition. So, in this study I selected fourth year basic BSc nursing students.

The present study revealed that one-minute preceptorship model is effective to improve clinical skills of nursing under graduate students. Students in experimental group agreed that one-minute preceptor method of teaching has helped them to improve clinical skills, self-confidence, communication and their critical thinking. In community they have to work independently with very less resources. So, one-minute preceptor model helped them to take decision.

In this study perception of experimental group students regarding OMP mean score and standard deviation was 45.87 \pm 3.40 respectively. Most of the students strongly agreed for why they were correct or incorrect (4.06), students understood the general rule what the researcher told them (4), OMP helped to gain confidence (4.03), they agree for the environment created by OMP (4.03) and students agreed that OMP helped to improve clinical skills (4.3).

Response assessment was done by using five-point Likert scale from both the group. Response mean score and standard deviation of experimental group and control group students was $46.50 \pm 2.46,35.60 \pm 3.60$ respectively. Comparison was done between the experimental group and control group $t$ value was 12.80 and $\mathrm{P}$-value was $\mathrm{P}=0.00$. So, it is proved that is significant. OMP model was effective to improve to develop clinical skills in nursing undergraduate students.

According to the result OMP was better as compare to traditional teaching method. Experimental group students had good learning experience. Their clinical skills improved. OMP teaching method helped in analysis of signs and symptoms of disease condition and to make diagnosis of the disease. In this teaching method, feedback received by students helped them to know their strength and weakness.

An interventional study conducted by Chandrakala R Iyer, G Nanditha, Janaki Raman on one-minute preceptor as an effective teaching and learning method for paediatric internship to implement OMP in our busy paediatric outpatient department (OPD) to train the interns and to know if it is an effective teaching technique. Researcher used Likert scale to evaluate OMP model and 15 interns were the participants posted in paediatric ward were the samples. Result showed that the average scores of questions went up from 1.3 and 3.1 in pre-project questionnaire to average scores of 2.3 and 4.1 in post-project questionnaire on a 5-point Likert scale. This shows OMP as an effective teaching method over traditional teaching method for interns at paediatric OPD. Thus, OMP was a simple, individualised and focused teaching method to the interns. OMP should be implemented in paediatric OPD to train the interns on common paediatric problems.

It was also found to be an interesting way of learning. The students also agreed that they were guided in a very methodical way where the clinical facilitator questioned them which provoked them to think and come up with a solution later, they were appreciated for the positive aspects of care and the teacher also provided general rules and concepts of care which made them gain lots of experience of learning with 5MP. ${ }^{10}$

This was a quasi-experimental interventional study conducted to assess the perception of teachers and students regarding OMP model. Total 60 undergraduate students and 12 faculty members were selected for the study. Faculty and students' perception were evaluated on 5-point Likert scale. Result of this study showed that the OMP model of teaching learning was well perceived by the students and faculty. Due to this, OMP model teaching skills of the faculty also improved. After applying this model, students were confident to work in clinical settings. OMP model helped to do self-directed learning and it included all three domains i.e., cognitive, affective and psychomotor. ${ }^{11}$

\section{Nursing Implications}

The findings will help nursing faculty to give more importance for planning and organising one-minute preceptor to communication skill, to take decision, to make diagnosis and critical thinking which will improve knowledge and clinical skills of students while learning.

\section{CONCLUSIONS}

OMP module is effective in improving clinical skills to manage minor ailments, to make decision, and critical thinking. It can be implemented to the final year undergraduate nursing students and post graduate nursing students.

\section{Limitations}

The study was conducted only among $4^{\text {th }}$ year nursing students. Sample size was small.

Data sharing statement provided by the authors is available with the full text of this article at jemds.com.

Financial or other competing interests: None.

Disclosure forms provided by the authors are available with the full text of this article at jemds.com. 


\section{REFERENCES}

[1] Jenishaadhikari. Clinical teaching. Health \& Medicine presented at UTC [cited 2020 Jul 8].

[2] Farzi S, Shahriari M, Farzi S. exploring the challenges of clinical education in nursing and strategies to improve it: a qualitative study. J Educ Health Promot 2018;7:115.

[3] Jamshidi L. The challenges of clinical teaching in nursing skills and lifelong learning from the standpoint of nursing students and educators. Procedia - Social and Behavirol Scicences 2012;46:3335-8.

[4] Community Nursing Diagnosis [cited Jul 8 2020].

[5] Dalton JM. Nursing diagnosis in a community health setting. Nurs Clin North Am 1979;14(3):525-31.

[6] Gerber L. Community health nursing: a partnership of care. Nursing 2012;42(Suppl Career):19-20.
[7] Gatewood E, De Gagne JC. The one-minute preceptor model: a systematic review. J Am Assoc Nurse Pract 2019; 31(1):46-57.

[8] One-minute-preceptor.pdf. [cited 2020 Dec 16] https://medschool.cuanschutz.edu/docs/librariesprovid er92/preceptor-materials/one-minutepreceptor.pdf?sfvrsn=e91a38b9_2

[9] Kowalski K. Use of the 1 - minute preceptor model as a tool in working with nurses. J Contin Edu Nurs 2017;48(8):345-6.

[10] Iyer CR, Nanditha G, Raman J. One minute preceptor as an effective teaching and learning method for pediatric internship: an interventional study. Indian Journal of Child Health 2017;4(2):184-7.

[11] the_one_minute_preceptor.pdf. [cited 2020 Dec 16]. https://www.gvsu.edu/cms4/asset/E6494549-9D1E60EB-

2FAF608662526253/the_one_minute_preceptor.pdf 